\title{
Cyclooxygenase-2 Expression and Relationship to Malignant Potential in Human Bladder Cancer
}

\author{
Ichiro Matsuzawa, ${ }^{a}$ Yukihiro Kondo, ${ }^{a}$ Go Kimura, ${ }^{a}$ Yoshitaka Hashimoto, ${ }^{a}$ Shigeo Horie, ${ }^{b}$ \\ Nobumasa Imura, ${ }^{c}$ Masao Akimoto, ${ }^{a}$ and Shuntaro Hara ${ }^{*, c}$ \\ ${ }^{a}$ Department of Urology, Nippon Medical School, Bunkyo-ku, Tokyo 113-8602, , ${ }^{b}$ Department of Urology, Faculty of Medicine, Univer- \\ sity of Tokyo, Bunkyo-ku, Tokyo 113-8655, and 'Department of Public Health and Molecular Toxicology, School of Pharmaceutical \\ Sciences, Kitasato University, Minato-ku, Tokyo 108-8641, Japan
}

(Received October 5, 2001; Accepted October 22, 2001)

\begin{abstract}
Cyclooxygenase (COX), which catalyzes the synthesis of prostaglandins from arachidonic acid, has two isoforms; COX-1 and COX-2. A large body of evidence exists to suggest that COX-2 is important in gastrointestinal cancer. In order to determine whether COX-2 is expressed in transitional cell carcinoma (TCC) of the human bladder as well as in gastrointestinal cancer, we investigated COX-2 expression in human TCC by Reverse Transcription-Polymerase Chain Reaction (RT-PCR) and immunohistochemical analysis, and we found that normal bladder epithelium did not express COX-2 and that COX-2 was markedly up-regulated in human bladder TCC. In nontumor tissues, COX-2 immunostaining signals were observed only in lymphoid follicles. Furthermore, the intensity and extent of COX-2 immunostaining in the bladder cancer tissues were scored and the relationship to tumor grade and stage was investigated. The levels of COX-2 expression were correlated with the tumor grade; from grades 1 to 3 , there was a stepwise increase in the COX-2 immunostaining score. These findings suggested that an increase in COX-2 expression may be associated with bladder carcinogenesis as well as gastrointestinal carcinogenesis, and that it may be useful as a biomarker in bladder cancer.
\end{abstract}

Key words — cyclooxygenase-2, prostaglandin, bladder cancer, transitional cell carcinoma

\section{INTRODUCTION}

Bladder cancer is the most common malignancy of the urinary tract, and the fourth or fifth leading cause of cancer-related death of men in Western industrialized countries. ${ }^{1)}$ The prognosis of patients with advanced bladder cancer is still extremely poor despite recent therapeutic advances, such as improved surgical techniques and perioperative combination chemotherapy. Therefore, future improvement in the survival rate of patients with bladder cancer might be possible through the development of novel indicator or therapeutic strategies.

Non-steroidal anti-inflammatory drugs (NSAIDs), including aspirin and piroxicam, which are candidate chemopreventive agents active against the development of colon cancer, ${ }^{2)}$ have chemopreventive potential against rat urinary bladder carcinogenesis induced by $N$-butyl- $N$-(4-hydro-

*To whom correspondence should be addressed: Department of Public Health and Molecular Toxicology, School of Pharmaceutical Sciences, Kitasato University, Minato-ku, Tokyo 108-8641, Japan. Tel.: +81-3-5791-6265; Fax: +81-3-3442-4146; E-mail: haras@pharm.kitasato-u.ac.jp xybutyl)nitrosamine. ${ }^{3,4)}$ The chemopreventive mechanisms of NSAIDs remain to be elucidated in detail, but have been postulated to involve their abilities to inhibit cyclooxygenase (COX) activity. COX catalyzes the synthesis of prostaglandins from arachidonic acid. And there are two isoforms of COX: one is constitutively expressed (COX-1) and other is inducible (COX-2). The COX-2 gene is an immediate early-response gene that is induced by growth factors, oncogenes, carcinogens, and tumor-promoting phorbol esters. ${ }^{5}$ Multiple lines of evidence suggest that COX-2 is important in carcinogenesis, and COX-2 is up-regulated in transformed cells $s^{6}$ and in various forms of gastrointestinal cancer, ${ }^{7-10)}$ whereas levels of COX-1 are relatively constant. Moreover, a null mutation for COX-2 resulted in a marked reduction in the number and size of intestinal polyps in APC mice, a murine model of familial adenomatous polyposis. ${ }^{11)}$ In addition to the genetic evidence implicating COX-2 in tumorigenesis, newly developed selective inhibitors of COX-2 protect against gastrointestinal tumor formation. ${ }^{12)}$

In the present study, we investigated whether COX-2 was up-regulated in human bladder cancer 
as well as in gastrointestinal cancer. Our data show that levels of COX-2 are increased in human bladder transitional cell carcinoma (TCC) and that COX2 may be used as a biomarker in bladder cancer, and also raise the possibility that selective inhibitors of COX-2 may be useful in the prevention or treatment of bladder TCC.

\section{MATERIALS AND METHODS}

Tissue Samples —_ Formalin-fixed urinary bladder tissue samples from patients with bladder tumors and normal bladders were obtained from the Department of Urology, Nippon Medical School. Snap-frozen bladder sections from patients undergoing transurethral resection of bladder tumor or total cystectomy at the Nippon Medical School were also evaluated for COX-2 mRNA by PCR. Informed consent was obtained from each patient. Complete pathology reports were available on all tissue samples. The grade of tumors was determined according to criteria adopted by WHO.

Reverse Transcription-Polymerase Chain Reaction (RT-PCR) - Total RNA was isolated according to the acid guanidinium thiocyanate procedure. RT-PCR was performed using COX-2 specific primers, ${ }^{13)}$ 5'-GGTCTGGTGCCTGGTCTGATGATG- ${ }^{\prime}$ and $5^{\prime}$-GTCCTTTCAAGGAGAATGGTGC- $3^{\prime}$ and $5 \mu \mathrm{g}$ total RNA as templates by ReadyTo-Go RT-PCR Beads (Amersham Pharmacia Biotech, U.K.). The PCR products were separated by electrophoresis on $1 \%$ agarose gel and visualized by ethidium bromide staining. For southern blot analysis, the PCR products were then transferred to a nylon membrane and hybridized with $\left[{ }^{32} \mathrm{P}\right]$-labeled human COX-2 probe.

Immunohistochemistry — Tissues were fixed in formalin, embedded in paraffin, cut into $2.5 \mu \mathrm{m}$ sections and mounted onto polylysine-coated slides. Sections were dewaxed in xylene and rehydrated in descending alcohol. They were immersed in $0.3 \%$ hydrogen peroxide to block endogenous peroxidase activity, microwaved in $\mathrm{pH} 6.0$ citrate-phosphate buffer for antigen retrieval, and incubated with $10 \%$ normal goat serum to block nonspecific binding. Rabbit polyclonal antibody specific for COX-2 was then applied as the primary antibody, followed by a standard staining procedure using Histofine SAB$\mathrm{PO}(\mathrm{R})$ kit (Nichirei, Tokyo, Japan). The immunohistochemical expression of COX-2 in the tumor cells was examined independently by two patholo-

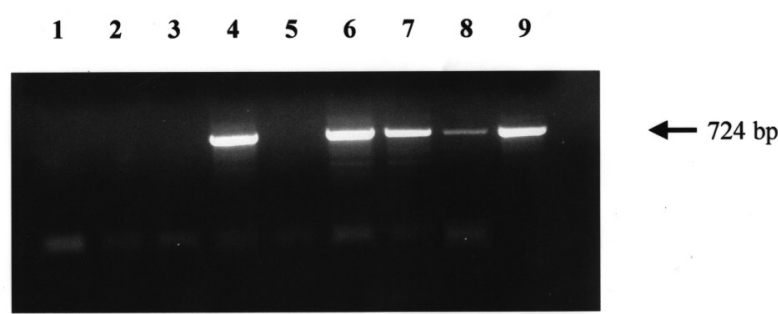

Fig. 1. RT-PCR Analysis of COX-2 mRNA Expression in Human Urinary Bladder

Seven tissue samples [two normal bladder tissues (lanes 1 and 2), four grade 1 bladder tumors (lanes 3 to 6) and three grade 2 bladder tumors (lanes 7 to 9)] were analyzed for COX-2 mRNA expression by RT-PCR

gists using light microscopy. The intensity of COX2 staining was scored in each specimen on a scale of 0 to 3 , in which $0=$ negative staining, $1=$ weakly positive staining, 2 = moderately positive staining, and $3=$ strongly positive staining. The extent of positive tumor cells was determined semiquantitatively by assessing the whole tumor section, and each sample was scored on a scale of 0 to 4 , in which $0=$ negative; $1=$ positive staining in $1 \%$ to $25 \%$ of cells; 2 , in $26 \%$ to $50 \%$; 3 , in $51 \%$ to $75 \%$; and 4 , in $76 \%$ to $100 \%$. Immunoreactivity for COX2 was finally compared statistically using the sum of the scores in each histological category score, as reported previously. ${ }^{14)}$

Statistical Analysis — Results were analyzed using the Mann-Whitney U-test. A difference between groups of $p<0.05$ was considered significant.

\section{RESULTS}

COX-2 mRNA Levels in Human Bladder Cancer

Seven tissue samples (two normal bladder, four grade 1 and three grade 2 tumors) were analyzed for COX-2mRNA expression by RT-PCR. As shown in Fig. 1, COX-2 702 bp cDNA fragments were amplified in two of four grade 1 tumors and all of three grade 2 tumors, although they were not amplified in any of the normal bladder tissues.

\section{COX-2 Protein Expression in Human Bladder Tissues}

To investigate the expression and location of the COX-2 protein, an immunohistochemical study was performed in the normal and cancerous bladder tissues. Pathological grade and stage of 51 bladder tumor samples are summarized in Table 1. All cases of grade 1 tumors showed pT1. Samples with a 
Table 1. Pathological Stage and Tumor Grade

\begin{tabular}{ccccc}
\hline \hline & pT1 & pT2 & pT3 & \\
\hline Grade1 & 12 & 0 & 0 & 12 \\
Grade2 & 19 & 1 & 4 & 24 \\
Grade3 & 3 & 6 & 6 & 15 \\
\hline & 34 & 7 & 10 & 51 \\
\hline
\end{tabular}

higher grade tended to show a higher pathological stage and $80 \%$ of grade 3 cases showed invasive tumor (more than or equal to pT2). Positive immunoreactivity to COX-2 protein was observed in 50 of 51 TCC samples. As shown in Fig. 2, the staining intensity of COX-2-positive TCC varied markedly between different tumors. We divided tumor samples on the basis of the intensity of immunostaining into four categories, 0 (negative), 1 (weak), 2 (moderate) and 3 (strong). The typical immunostaining pattern of COX-2 in the cases of categories 1,2 and 3 is shown in Figs. 2A, 2B and 2C, respectively. In non-tumor tissues, strong signals were observed only in the lymph follicles (Fig. 2D). The intensity of lymphoid follicles was 2 (moderate).

The intensity and extent (\% positive area) of COX-2 staining in each cancer grade are summarized in Table 2. In order to investigate the relationship between COX-2 expression and cancer grade, the COX-2 scores were next evaluated in the bladder tumor specimens (Fig. 3). The mean value of the COX-2 score in each grade was as follows: grade 1, $3.25 \pm 1.96$; grade 2, $4.41 \pm 1.58$; and grade 3 , $4.93 \pm 1.97$. The score was higher in the high grade cases with a significant difference between grades 1 and $2(p<0.05)$ and grades 1 and $3(p<0.01)$. Additionally, we evaluated the relationship between COX-2 expression and tumor stage (Fig. 4). The mean value of the COX-2 score in low and high stage was $1.65 \pm 0.13$ and $2.24 \pm 0.20$, respectively. The

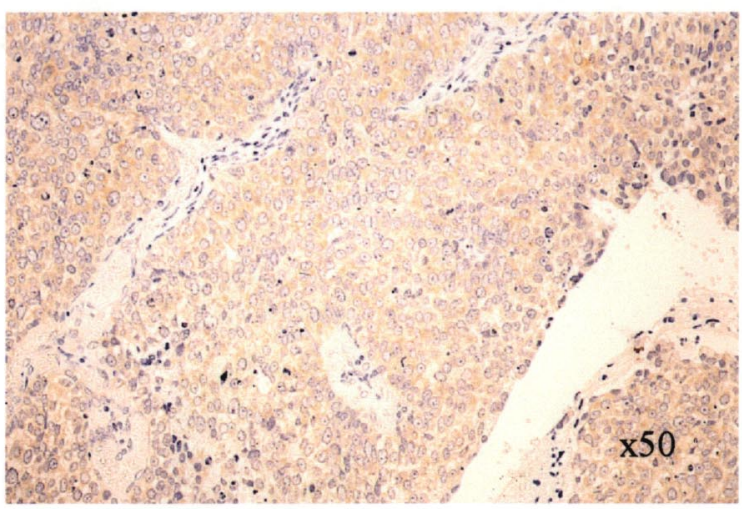

B



$\mathrm{C}$



D

Fig. 2. Immunohistochemical Analysis of COX-2 Expression in Bladder Tumor

The tumor grade of tissue samples A, B and C were grades 1, 2 and 3, respectively. The immunostaining intensity shown in A, B and C was distinguished as categories 1 (weak), 2 (moderate) and 3 (strong), respectively. COX-2 was not expressed in the normal urinary bladder, but the intensity of lymphoid follicles was 2 (moderate) (D). 
Table 2. COX-2 Expression in Transitional Cell Carcinoma of Bladder

\begin{tabular}{lccccc}
\hline \hline & \multicolumn{5}{c}{ Intensity } \\
\cline { 2 - 6 } & 0 (negative) & 1 (weak) & 2 (moderate) & 3 (strong) & mean \pm S.D. \\
\hline Grade1 $(n=12)$ & 1 & 8 & 3 & 0 & $1.17 \pm 0.58^{*}$ \\
Grade2 $(n=24)$ & 0 & 8 & 12 & 4 & $1.83 \pm 0.70^{* *}$ \\
Grade3 $(n=15)$ & 0 & 2 & 5 & 8 & $2.36 \pm 0.75$ \\
\hline & $0(0-25 \%)$ & $1(26-50 \%)$ & $2(51-75 \%)$ & $3(76-100 \%)$ & mean \pm S.D. \\
\cline { 2 - 6 } & 5 & 3 & 1 & 3 & $2.08 \pm 1.38$ \\
Grade1 $(n=12)$ & 3 & 7 & 11 & 3 & $2.58 \pm 0.88$ \\
Grade2 $(n=24)$ & 4 & 2 & 5 & 4 & $2.57 \pm 1.22$ \\
Grade3 $(n=15)$ & \multicolumn{5}{c}{ Extent } \\
\hline *: Significantly different between grade 1 and 2 or 3 $(p<0.01) . * *:$ Significantly different between grade 2 and \\
$3(p<0.05)$.
\end{tabular}

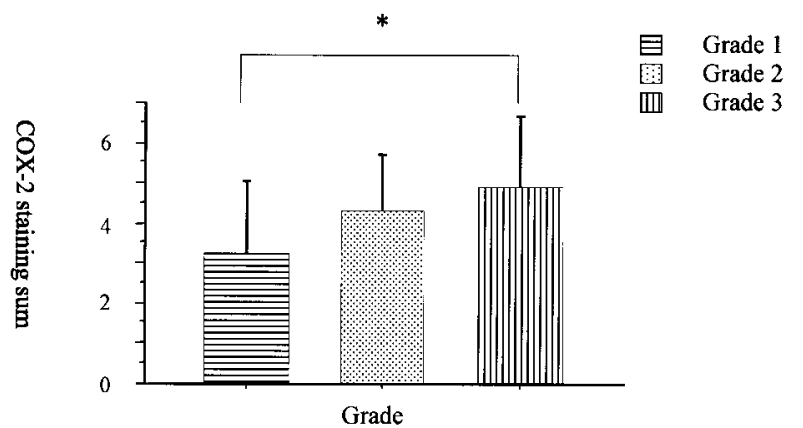

Fig. 3. The Relationship between COX-2 Score and Tumor Grade of Bladder Tumor

The COX-2 scores were evaluated from COX-2 intensity and the extent in the bladder tumor specimens. *Significantly different between grades 1 and 3 by Mann-Whitney U-test $(p<0.01)$.

high stage COX-2 score was significantly higher than that of the low stage.

\section{DISCUSSION}

There is ample evidence to suggest an important role for COX-2 in cancer. Many reports indicate that COX-2 is up-regulated in most human tumors such as colon, stomach, lung and mammary tumors. ${ }^{7-10,13-15)}$ In the present study, we found that COX-2 was also markedly up-regulated in human bladder TCC. We further showed that from grades 1 to grade 3 , there was a stepwise increase in the COX2 score. Our findings indicate that COX-2 might play an important role in bladder tumor development and progression, and it might be useful as a biomarker in bladder cancer.

During the preparation of this manuscript, four groups independently reported the presence of COX2 in human bladder TCC. ${ }^{16-19)}$ Although our data indicated that almost all of TCC (98\%) including low-

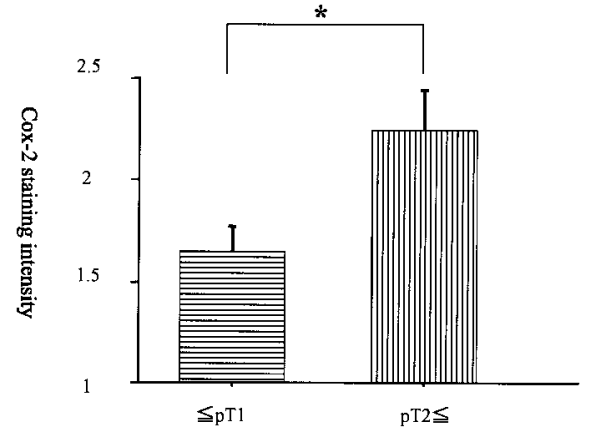

Fig. 4. The Relationship between COX-2 Score and Tumor Stage

Low stage bladder tumor included lower than pT2. The COX-2 scores were evaluated from COX-2 intensity and extent in the bladder tumor specimens. *Significantly different between the low stage and the high stage tumor by Mann-Whitney U-test $(p<0.05)$.

grade TCC were positive for COX-2, these recent reports indicated that only 34 to $84 \%$ of TCC were positive ${ }^{16-19)}$ and Kömhoff et al. did not detect any COX-2 expression in low-grade TCC. ${ }^{18)}$ Discrepancies in the immunohistochemical data may be due to the use of different antibodies and/or staining methods that affect both sensitivity and specificity.

The function of COX-2 in tumor development and progression remains to be fully elucidated. The most obvious possibility is that an overexpression of COX-2 leads to high levels of PGs in tumor tissues. This hypothesis is supported by the finding of elevated levels of PGs in cancer tissues compared with corresponding normal tissues. ${ }^{20,21)}$ Thus, PGs produced by COX-2 may subsequently facilitate tumor progression by acting as differentiation and growth factors, and as angiogenic agents. ${ }^{22)}$ Treatment with $\mathrm{PGE}_{2}$, as well as an overexpression of COX-2, inhibited programmed cell death and enhanced the tumorigenic potential of colonic epithelial cells. ${ }^{23-25)}$ It was also reported that ibuprofen in- 
hibited the invasion effect of UN-UC TCC cell line and that $\mathrm{PGE}_{2}$ recovered. ${ }^{26)}$ Furthermore, Watanabe et al. recently found that both gene disruption of $\mathrm{EP}_{1}$ receptor and treatment of $\mathrm{EP}_{1}$ antagonist inhibited azoxymethane-induced colon carcinogenesis. ${ }^{27)}$ $\mathrm{PGE}_{2}$ produced by $\mathrm{COX}-2$ may mediate carcinogenic changes by acting on $\mathrm{EP}_{1}$ receptor.

In human bladder tissues, COX-2 protein was detected in lymphoid follicles as well as in TCC (Fig. 2D). This observation is consistent with the previous reports that the expression of COX-2 is induced by inflammatory stimuli and that inflammatory leukocytes express high levels of COX-2 protein. ${ }^{28,29)}$ It has also been reported that eosinophilic or irritant-induced cystitis is a risk factor for bladder cancer ${ }^{30)}$ and the expression of COX-2 in lymphoid follicles may be associated with bladder carcinogenesis.

Clinically, bladder tumor is a frustrating tumor since superficial bladder tumor has a recurrent potential and invasive bladder tumor prognosis is still poor despite therapeutic advances. It was recently reported that COX-2 specific inhibitors, nimesulide and celecoxib, had chemopreventive effects in a rodent model of superficial bladder cancer. ${ }^{31,32)}$ These findings suggested that COX-2 inhibitor might prevent human bladder tumor and have a useful potential bladder tumor control or treatment. However, since the antitumor effects remain to be elucidated, future clinical study is necessary.

Acknowledgements This study was supported in part by a Grant-in-Aid for Scientific Research (B: No. 11671586 and 11671585) from The Ministry of Education, Science, Sports and Culture of Japan.

\section{REFERENCES}

1) Parker, S. L., Tong, T., Bolden, S. and Wingo, P. A. (1997) Cancer statistics, 1997. CA Cancer J. Clin., 47, 5-27.

2) Thun, M. J., Namboodiri, M. M. and Heath, C. W., Jr. (1991) Aspirin use and reduced risk of fatal colon cancer. N. Engl. J. Med., 325, 1593-1596.

3) Cohen, S. M., Zenser, T. V., Murasaki, G., Fukushima, S., Mattammal, M. B., Rapp, N. S. and Davis, B. B. (1981) Aspirin inhibition of $N$-[4-(5nitro-2-furyl)-2-thiazolyl]formamide-induced lesions of the urinary bladder correlated with inhibition of metabolism by bladder prostaglandin endoperoxide synthetase. Cancer Res., 41, 3355-3359.

4) Moon, R. C., Kelloff, G. J., Detrisac, C. J., Steele,
V. E., Thomas, C. F. and Sigman, C. C. (1993) Chemoprevention of OH-BBN-induced bladder cancer in mice by piroxicam. Carcinogenesis, 14, 14871489.

5) Herschman, H. R. (1996) Prostaglandin synthase 2. Biochim. Biophys. Acta, 1299, 125-140.

6) Subbaramaiah, K., Telang, N., Ramonetti, J. T., Araki, R., DeVito, B., Weksler, B. B. and Dannenberg, A. J. (1996) Transcription of cyclooxygenase- 2 is enhanced in transformed mammary epithelial cells. Cancer Res., 56, 4424-4429.

7) Eberhart, C. E., Coffey, R. J., Radhika, A., Giardiello, F. M., Ferrenbach, S. and DuBois, R. N. (1994) Upregulation of cyclooxygenase 2 gene expression in human colorectal adenomas and adenocarcinomas. Gastroenterology, 107, 1183-1188.

8) Sano, H., Kawahito, Y., Wilder, R. L., Hashiramoto, A., Mukai, S., Asai, K., Kimura, S., Kato, H., Kondo, M. and Hla, T. (1995) Expression of cyclooxygenase-1 and -2 in human colorectal cancer. Cancer Res., 55, 3785-3789.

9) Kargman, S. L., O’Neill, G. P., Vickers, P. J., Evans, J. F., Mancini, J. A. and Jothy, S. (1995) Expression of prostaglandin $\mathrm{G} / \mathrm{H}$ synthase- 1 and -2 protein in human colon cancer. Cancer Res., 55, 2556-2559.

10) Ristimäki, A., Honkanen, N., Jankala, H., Sipponen, P. and Harkonen, M. (1997) Expression of cyclooxygenase-2 in human gastric carcinoma. Cancer Res., 57, 1276-1280.

11) Oshima, M., Dinchuk, J. E., Kargman, S. L., Oshima, H., Hancock, B., Kwong, E., Trzaskos, J. M., Evans, J. F. and Taketo, M. M. (1996) Suppression of intestional polyposis in $A p c^{\Delta 716}$ knockout mice by inhibition of cyclooxygenase 2. Cell, 87, 803-809.

12) Ritland, S. R. and Gendler, S. J. (1999) Chemoprevention of intestinal adenomas in the $A p c^{\text {Min }}$ mouse by piroxicam: kinetics, strain effects and resistance to chemosuppression. Carcinogenesis, 20, 51-58.

13) Chan, G., Boyle, J. O., Yang, E. K., Zhang, F., Sacks, P. G., Shah, J. P., Edelstein, D., Soslow, R. A., Koki, A. T., Woerner, B. M., Masferrer, J. L. and Dannenberg, A. J. (1999) Cyclooxygenase-2 expression is up-regulated in squamous cell carcinoma of the head and neck. Cancer Res., 59, 991-994.

14) Koga, H., Sakisaka, S., Ohishi, M., Kawaguchi, T., Taniguchi, E., Sasatomi, K., Harada, M., Kusaba, T., Tanaka, M., Kimura, R., Nakashima, Y., Nakashima, O., Kojiro, M., Kurohiji, T. and Sata, M. (1999) Expression of cyclooxygenase-2 in human hepatocellular carcinoma: relevance to tumor dedifferentiation. Hepatology, 29, 688-696.

15) Hida, T., Yatabe, Y., Achiwa, H., Muramatsu, H., Kozaki, K. I., Nakamura, S., Ogawa, M., Mitsudomi, T., Sugiura, T. and Takahashi, T. (1998) Increased 
expression of cyclooxygenase 2 occurs frequently in human lung cancers, speciffically in adenocarcinomas. Cancer Res., 58, 3761-3764.

16) Mohammed, S. I., Knapp, D. W., Bostwick, D. G., Foster, R. S., Khan, K. N. M., Masferrer, J. L., Woerner, B. M., Snyder, P. W. and Koki, A. T. (1999) Expression of cyclooxygenase-2 (COX-2) in human invasive transitional cell carcinoma (TCC) of the urinary bladder. Cancer Res., 59, 5647-5650.

17) Shirahama, T. (2000) Cyclooxygenase-2 expression is up-regulated in transitional cell carcinoma and its preneoplastic lesions in the human urinary bladder. Clin. Cancer Res., 6, 2424-2430.

18) Kömhoff, M., Guan, Y., Shappell, H. W., Davis, L., Jack, G., Shyr, Y., Koch, M. O., Shappell, S. B. and Breyer, M. D. (2000) Enhanced expression of cyclooxygenase-2 in high grade human transitional cell bladder carcinomas. Am. J. Pathol., 157, 2935.

19) Ristimäki, A., Nieminen, O., Saukkonen, K., Hotakainen, K., Nordling, S. and Haglund, C. (2001) Expression of cyclooxygenase-2 in human transitional cell carcinoma of the urinary bladder. Am. $J$. Pathol., 158, 849-853.

20) Rigas, B., Goldman, I. S. and Levine, L. (1993) Altered eicosanoid levels in human colon cancer. $J$. Lab. Clin. Med., 122, 518-523.

21) Pugh, S. and Thomas, G. A. (1994) Patients with adenomatous polyps and carcinomas have increased colonic mucosal prostaglandin $\mathrm{E}_{2}$. Gut, 35, 675-678.

22) Prescott, S. M. and Fitzpatrick, F. A. (2000) Cyclooxygenase-2 and carcinogenesis. Biochim. Biophys. Acta, 1470, M69-M78.

23) Tsujii, M. and DuBois, R. N. (1995) Alterations in cellular adhesion and apoptosis in epithelial cells overexpressing prostaglandin endoperoxide synthase 2. Cell, 83, 493-501.

24) Tsujii, M., Kawano, S., Tsuji, S., Sawaoka, H., Hori, M. and DuBois, R. N. (1998) Cyclooxygenase regulates angiogenesis induced by colon cancer cells. Cell, 93, 705-716.

25) Sheng, H., Shao, J., Morrow, J. D., Beauchamp, R.
D. and DuBois, R. N. (1998) Modulation of apoptosis and Bcl-2 expression by prostaglandin $\mathrm{E}_{2}$ in human colon cancer cells. Cancer Res., 58, 362366.

26) Cook, G. P. and Hampton, J. A. (1997) Effects of ibuprofen on the in vitro invasiveness of a human transitional cell carcinoma. Anticancer Res., 17, 365-368.

27) Watanabe, K., Kawamori, T., Nakatsugi, S., Ohta, T., Ohuchida, S., Yamamoto, H., Maruyama, T., Kondo, K., Ushikubi, F., Narumiya, S., Sugimura, T. and Wakabayashi, K. (1999) Role of the prostaglandin $\mathrm{E}$ receptor subtype $\mathrm{EP}_{1}$ in colon carcinogenesis. Cancer Res., 59, 5093-5096.

28) Nanayama, T., Hara, S., Inoue, H., Yokoyama, C. and Tanabe, T. (1995) Regulation of two isozymes of prostaglandin endoperoxide synthase and thromboxane synthase in human monoblastoid cell line U937. Prostaglandins, 49, 371-382.

29) Niiro, H., Otsuka, T., Izuhara, K., Yamaoka, K., Ohshima, K., Tanabe, T., Hara, S., Nemoto, Y., Tanaka, Y., Nakashima, H. and Niho, Y. (1997) Regulation by interleukin-10 and interleukin- 4 of cyclooxygenase-2 expression in human neutrophils. Blood, 89, 1621-1628.

30) Burin, G. J., Gibb, H. J. and Hill, R. N. (1995) Human bladder cancer: evidence for a potential irritation-induced mechanism. Food Chem. Toxicol., 33, 785-795.

31) Okajima, E., Denda, A., Ozono, S., Takahama, M., Akai, H., Sasaki, Y., Kitayama, W., Wakabayashi, K. and Konishi, Y. (1998) Chemopreventive effects of nimesulide, a selective cyclooxygenase-2 inhibitor, on the development of rat urinary bladder carcinomas initiated by $N$-butyl- $N$-(4-hydroxybutyl)nitrosamine. Cancer Res., 58, 3028-3031.

32) Grubbs, C. J., Lubet, R. A., Koki, A. T., Leahy, K. M., Masferrer, J. L., Steele, V. E., Kelloff, G. J., Hill, D. L. and Seibert, K. (2000) Celecoxib inhibits $N$ butyl- $N$-(4-hydroxybutyl)nitrosamine-induced urinary bladder cancers in male B6D2F1 mice and female Fischer-344 rats. Cancer Res., 60, 5599-5602. 